OAK RIDGE NATIONAL LABORATORY

\section{UNION CARBIDE}

\title{
Impurity Transport During Neutral Beam Injection in the ISX-B Tokamak
}
R. C. Isler
E. C. Crume
D. E. Arnurius
L. E. Murray

OPERATED BY

UNION CARBIDE CORPORATION FOR THE UNITED STATES DEPARTMENT OF ENERGY 


\section{DISCLAIMER}

This report was prepared as an account of work sponsored by an agency of the United States Government. Neither the United States Government nor any agency Thereof, nor any of their employees, makes any warranty, express or implied, or assumes any legal liability or responsibility for the accuracy, completeness, or usefulness of any information, apparatus, product, or process disclosed, or represents that its use would not infringe privately owned rights. Reference herein to any specific commercial product, process, or service by trade name, trademark, manufacturer, or otherwise does not necessarily constitute or imply its endorsement, recommendation, or favoring by the United States Government or any agency thereof. The views and opinions of authors expressed herein do not necessarily state or reflect those of the United States Government or any agency thereof. 


\section{DISCLAIMER}

Portions of this document may be illegible in electronic image products. Images are produced from the best available original document. 
Printed in the United States of America. Available from National Technical Information Service

U.S. Department of Commerce

5285 Port Royal Road, Springfield, Virginia 22161

NTIS price codes-Printed Copy: A03; Microfiche A01

$A 02$

This report was prepared as an account of work sponsored by an agency of the United States Government. Neither the U nited States Government nor any agency thereof, nor any of their employees, makes any warranty, express or implied, or assumes any legal liability or responsibility for the accuracy, completeness, or usefulness of any information, apparatus, product, or process disclosed, or represents that its use would not infringe privately owned rights. Reference herein to any specific commercial product, process, or service by trade name, trademark, manufacturer, or otherwise, does not necessarily constitute or imply its endorsement, recommendation, or favoring by the United States Government or any agency thereof. The views and opinions of authors expressed herein do not necessarily state or reflect those of the United States Government or any agency thereof. 
ORNL/TM-7472

Dist. Category UC-20 f

Contract No. W-7405-eng-26

FUSION ENERGY DIVISION

IMPURITY TRANSPORI DURING NEUTRAL BEAM INJECTION

IN THE ISX-B TOKAMAK

R. C. Isler

E. C. Crume

D. E. Arnurius

L. E. Murray

Date Published - October 1980

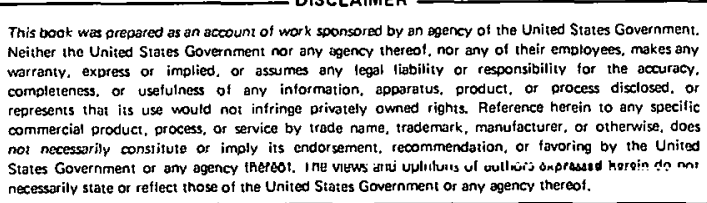

NOTICE This document contains information of a preliminary nature.

It is subject to revision or correction and therefore does not represent a

final report.

Prepared by the OAK RIDGE NATIONAL LABORATORY

Oak Ridge, Tennessee 37830

operated by

UNION CARBIDE CORPORATION

for the

DEPARTMENT OF ENERGY 
THIS PAGE

\section{WAS INTENTIONALLY \\ LEFT BLANK}




\section{CONTENTS}

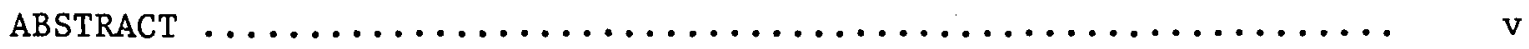

IMPURITY TRANSPORT DURING NEUTRAL BEAM INJECTION

IN THE ISX-B TOKAMAK $\ldots \ldots \ldots \ldots \ldots \ldots \ldots \ldots \ldots \ldots \ldots \ldots \ldots \ldots \ldots$

ACKNOWLEDGMENTS $\ldots \ldots \ldots \ldots \ldots \ldots \ldots \ldots \ldots \ldots \ldots \ldots \ldots \ldots \ldots \ldots \ldots \ldots$

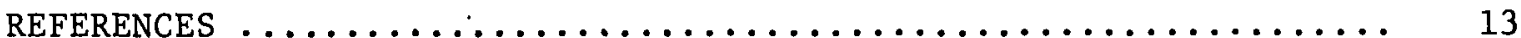


THIS PAGE

WAS INTENTIONALLY

LEFT BLANK 


\begin{abstract}
In ohmically heated ISX-B discharges, both the intrinsic iron impurity ions and small amounts of argon introduced as a test gas accumulate at the center of the plasma. But during certain beam-heated discharges, it appears that this accumulation does not take place. These results may reflect the conclusion of Stacey and Sigmar that momentum transferred from the beams to the plasma can inhibit inward impurity transport.
\end{abstract}


IMPURITY TRANSPORT DURING NEUTRAL BEAM INJECTION IN THE ISX-B TOKAMAK

One of the concerns about the use of neutral beam injection as a method of auxiliary heating in tokamaks is that additional impurities may be introduced into the discharge due to sputtering by high energy atoms or ions. However, Stacey and Sigmar ${ }^{1}$ have shown theoretically that the consequences of this effect may be ameliorated by a reduction of the radial impurity influx due to the momentum which the beams transfer to the plasma. For a single impurity species, they demonstrate that although the direct influence of coinjection (in the direction of the plasma current) on the impurity is to enhance its inward transport, ${ }^{2}$ the first-order flows in the flux surfaces are simultaneously altered in such a way that outward transport may be the net result. We analyze spectral data from two sequences of discharges in the Impurity Study Experiment (ISX-B) tokamak which indicate that during injection the impurity influx is indeed strongly reduced, or even reversed, in the innex hallf of the plasma.

The plasmas we discuss here are produced in deuterium with an ohmic heating current of $110 \mathrm{kA}$. For the injection case, $500 \mathrm{~kW}$ of neutral hydrogen is injected between 70 and $170 \mathrm{~ms}$ in discharges which last a total of $200 \mathrm{~ms}$. The electron heating produced by the beam results in a central temperature of $1400 \mathrm{eV}$, as contrasted with $750 \mathrm{eV}$ for the noninjected case. In all instances deuterium gas is bled into the discharge from $30 \mathrm{~ms}$ until the end of the shot in order to raise the electron concentration. The time behavior of $\overline{n_{e}}$ is shown in Fig. 1. Without injection, the density continues to rise until the plasma disrupts around $150 \mathrm{~ms}$. With injection, the density "clamps" at $110 \mathrm{~ms}$ and no 


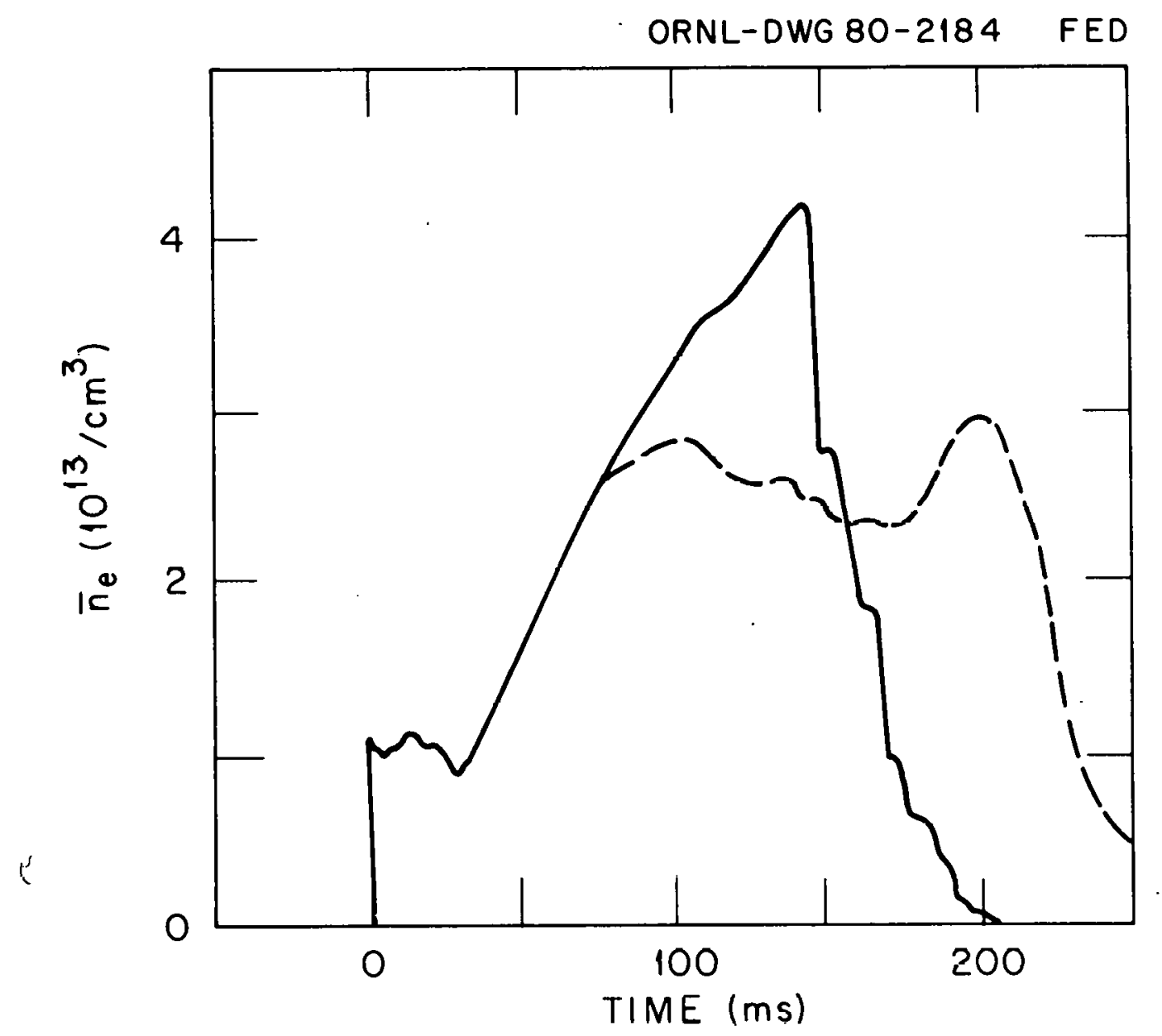

Fig. 1. Evolution of the line-averaged elcctron concentration, $\overline{n_{e}}$, in plasmas with (dashed line) and without (solid line) neutral beam injoctinn. 
disruption occurs. This clamp is characteristic of most injection discharges in ISX-B. ${ }^{3}$ Although the total electron concentration is limited, the radial profiles are not strongly affected. The mechanism by which clamping occurs is not understood, but it may reflect an alteration in the basic transport processes such as we discuss for the impurities. The temporal evolutions of two argon lines ${ }^{4}$ are shown in Fig. 2. Argon is introduced in a short ( $\sim 4-\mathrm{ms}$ ) puff at $100 \mathrm{~ms}$, and the integrated radiation along a central chord is observed. Extensive use is made of the RECYCL $\operatorname{code}^{5}$ to analyze spectral data. This code enables us to calculate the radial distributions of line emissions of various ionization stages for assumed total impurity profiles and transport velocities. The Ar VII line is computed to be emitted from a shell about $2 \mathrm{~cm}$ wide centered near $20 \mathrm{~cm}$ (the plasma minor radius is $26 \mathrm{~cm}$ ). In both injection and noninjection discharges, the Ar VII radiation attains a constant level within a few milliseconds of introducing the gas. This behavior is indicative of a constant flux through the plasma periphery during the entire shot, i.e., of anomalous outward diffusion that causes the argon to recycle rapidly in the edge. ${ }^{6}$

The Ar XVI line exhibits strikingly different behavior for the two sequences of shots. It is emitted mainly inside a radius of $13 \mathrm{~cm}$, and calculations using transport velocities of $1-2 \mathrm{~cm} / \mathrm{ms}$, to agree with the observed onset of the radiation, indicate that significant emission from Ar XVI should take place from the plasma center in both cases. This lithium-like ion thus provides a useful monitor of the argon concentration in the interior of the discharge. It is seen in Fig. 2 that during injection the Ar XVI radiation, similar to the Ar VII radiation, reaches a steady state. The relative intensities indicate that the argon distribution is not strongly peaked at the center. In contrast, there is a continued rise in the Ar XVI signal without injection. This rise is much larger than can be explained by the increasing electron concentration, and it indicates that, even in view of the rapid recycling at the plasma edge, there is a slow, continual accumulation of argon in the plasma interior. Therefore, it appears that the presence of neutral beam injection does alter the transport sufficiently in the interior of the plasma to prevent accumulation of the test impurity. - 


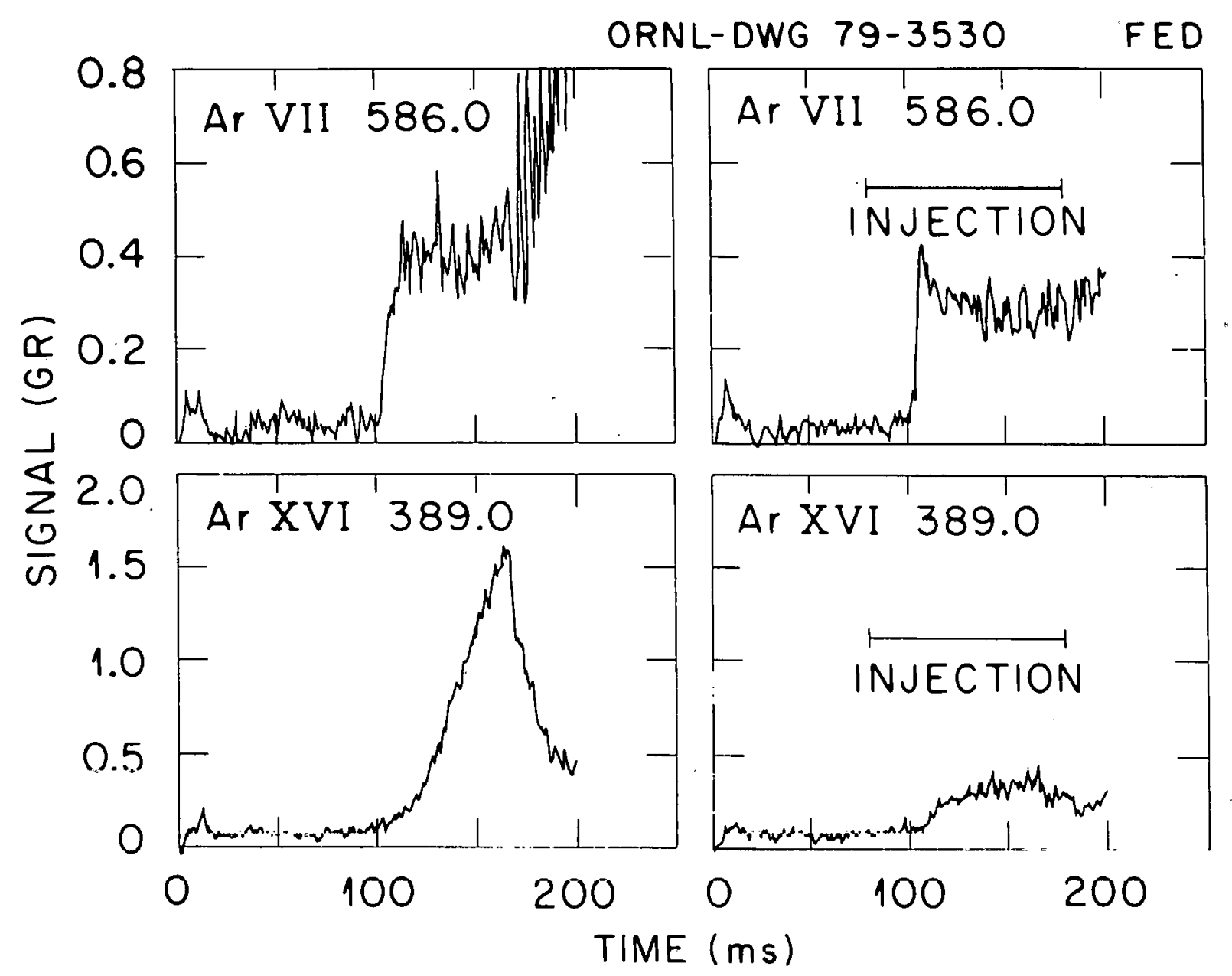

Fig. 2. Spectral emissions from Ar VII and Ar XVI. The argon is introduced into the plasma in a 4-ms burst at 100 ms after breakdown. 
We have also analyzed the iron radiation from the same sequences for which the argon was studied. Figures 3 and 4 illustrate the time behavior of several spectral lines. Again it is observed that the interior ions, such as Fe XVIII and Fe XIX, evidence accumulation in the ohmic heating case but that the intensities during injection are quite low. Also, the $\mathrm{Fe} X \mathrm{XX}$ radiation is barely above the background level, even though this ion should be abundant at the electron temperatures achieved during injection. In contrast, it is immediately obvious that the iron concentration in the exterior of the plasma rises shortly after injection; for a fixed iron density profile, the radiation from stages such as Fe IX would be expected to decrease by a factor of about three since this ion radiates from a much narrower shell in the hotter plasma.

It is possible to obtain quantitative, although not highly accurate, assessments of the total iron behavior throughout the plasma volume by adjusting profiles in the RECYCL code until satisfactory agreement is obtained between computed and measured emission rates. The accuracies of the individual computed rates are believed to be no better than a factor of two due to uncertainties in the atomic physics and in the transport velocities of the impurities. The calibration of the monochromator introduces an additional uncertainty in the interpretation of the data, and we estimate that our inferred profiles may be in error by a factor of three.

The profiles obtained for the two sequences at $141 \mathrm{~ms}$ are shown in Fig. 5. The noninjection concentration peaks at the center, as might be expected. However, there appears to be no way to explain the data obtained during injection without inferring a profile that has a maximum near one-half of the plasma minor radius. If the iron concentration is assumed to be nondecreasing inside $15 \mathrm{~cm}$, radiation from $F e X I X$ and Fe XX should be respectively five and ten times the observed values. Consequently, the iron profile must be "hollow," and even if there is a larger influx of iron during injection, it must accumulate at some intermediate radius. Despite the problems inherent in inferring radial concentrations from line-averaged data, it seems that the profiles of Fig. 5 are at least qualitatively correct. 
ORNL-DWG 80-2183R. FED
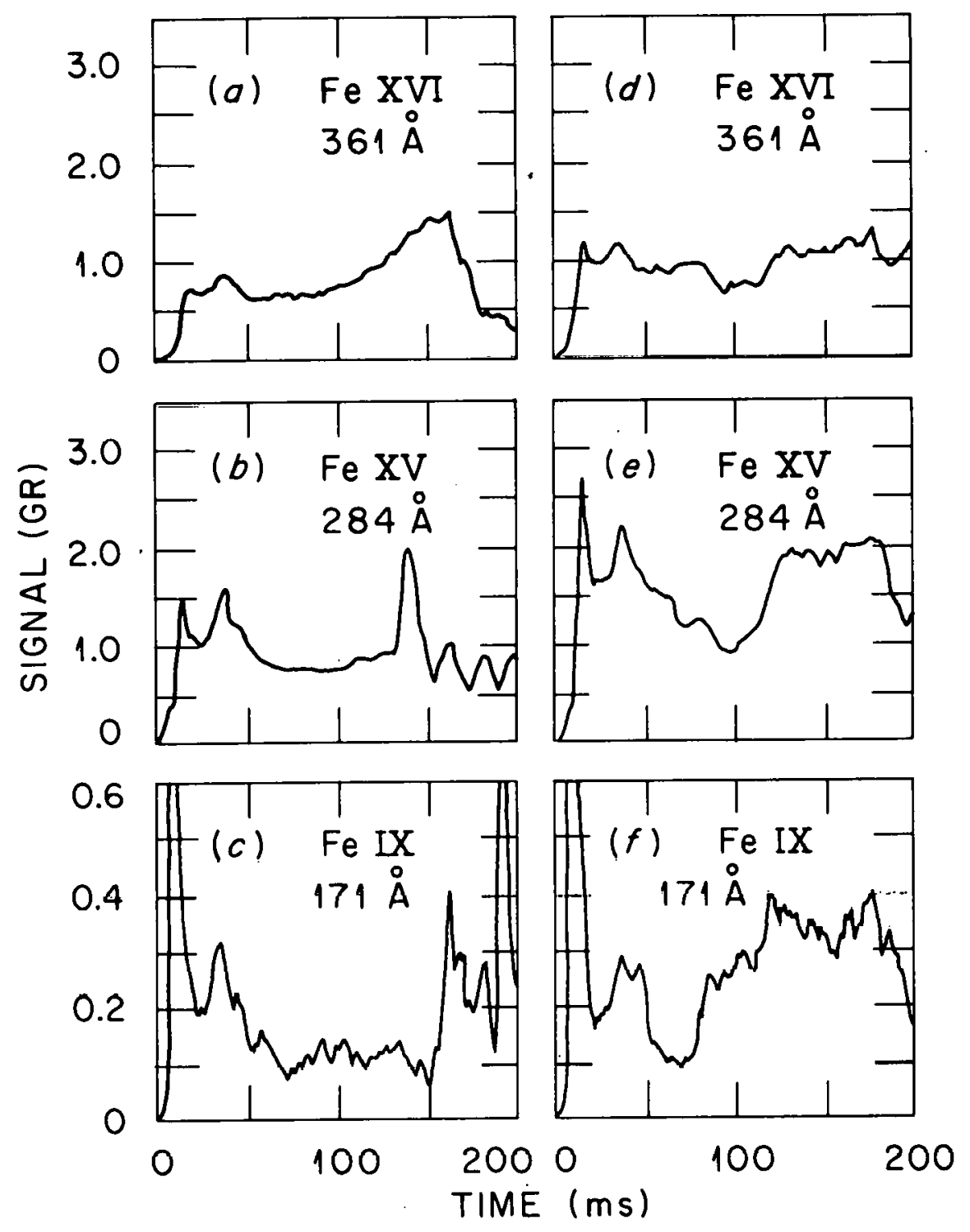

Fig. 3. Comparison of emissions from Fe IX, Fe XV, and $\mathrm{Fe}$ XVI. Figures 3(a)-3(c) are without injection; Figs. 3(d) $-3(f)$ are with injection. Injection lasts from $70-170 \mathrm{~ms}$. 
ORNL-DWG $80-2182$ FED

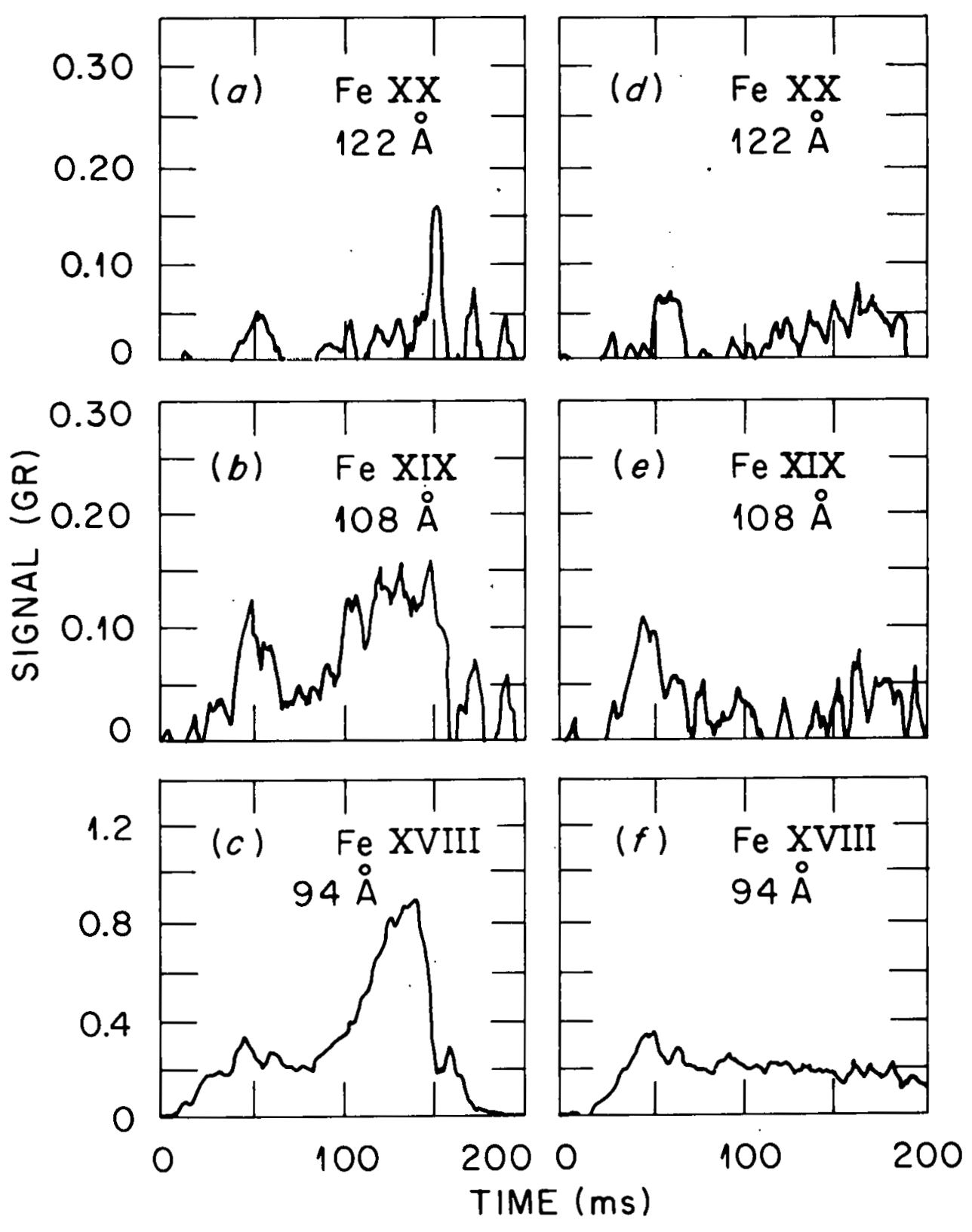

Fig. 4. Comparison of emissions from Fe XVIII, Fe XIX, and $\mathrm{Fe} \mathrm{XX}$. Figures $4(\mathrm{a})-4(\mathrm{c})$ are without injection; Figs. 4(d)-4(f) are with injection. Injection lasts from $70-170 \mathrm{~ms}$. 


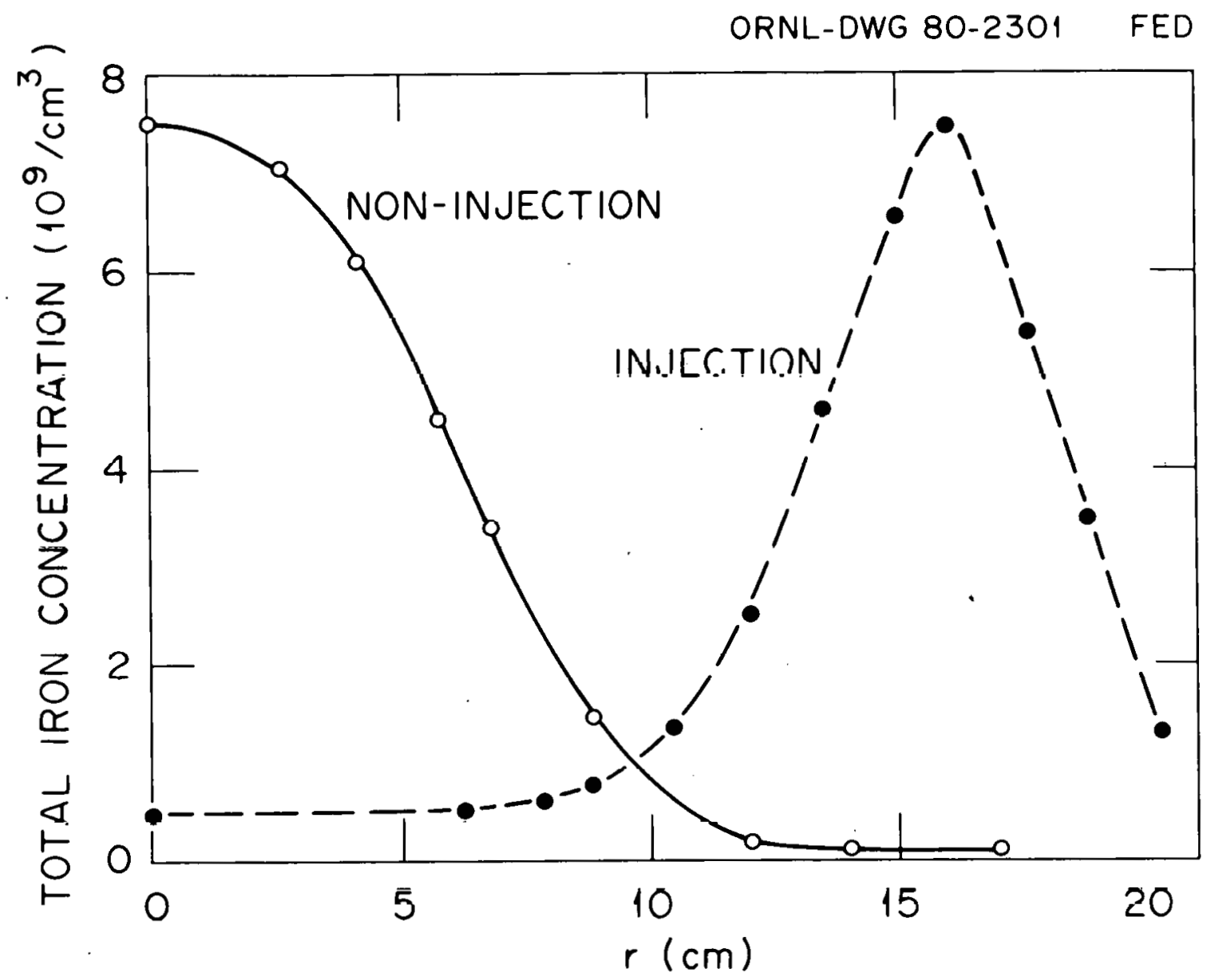

Fig. 5. Profiles of total iron coneentration with injection (dashed line) and without injection (solid line). 
Direct comparisons of our analysis with the theory of Stacey and Sigmar are not possible at present. The detailed physics of the external drag terms that appear in their formalism is not well understood, and in reality we must consider a multicomponent rather than a two-component plasma (oxygen and carbon are the dominant impurities). However, it is worth examining their criterion for flow reversal under the assumption that the theoretical terms containing the beam momentum transferred to the plasma ions dominate those which contain the momentum transferred to the impurities. In this case, the requirement as a function of plasma radius can be expressed as

$$
I_{b} H(r)>\frac{n_{i} m_{i} \nu_{i z}\left|\frac{1}{Z_{i} n_{i}} \frac{\partial P_{i}}{\partial r}\right| 2 \pi R_{0}}{m_{b} v_{b}\left|B_{p o}\right|} \cdot \frac{\beta_{z}}{\beta_{i}\left(I+\beta_{z}\right)+\beta_{z}}
$$

in the mixed collisionality regime of the ISX experiments. Here, $I_{b}$ is the total neutral beam current, $H(r)$ is the normalized power deposition profile, and $B_{i}$ and $B_{z}$ respectively represent the ratios of plasma ion and impurity ion drag frequencies to the collision frequency, $v_{i z}$. If this inequality is satisfied everywhere in the plasma, then no impurity penetration may be expected from the mechanisms considered in this theory, i.e., from interspecies collisional friction and momentum exchange from external sources. It is also worth noting that both the ion pressure gradient, $\partial \mathrm{P}_{i} / \partial \mathrm{r}$, and the poloidal field, $\mathrm{B}_{\mathrm{po}}$, approach zero as $r \rightarrow 0$, and in ISX discharges it appears that the former becomes small faster than the latter. In such circumstances the neutral beam requirements may be satisfied for small, but not large, values of $r$, and hollow impurity profiles could develop in principle. It is evident that our observations are in qualitative agreement with a possible result of Stacey and Sigmar's theory, but because of the uncertainties it cannot yet be said that they substantiate the calculations.

Finally, we note that particle transport problems are so complex that it is impossible to generalize the present results to all, if 
indeed to many, injection experiments in tokamaks. We believe that a broader scope of both experimental and theoretical studies of the influence of neutral beams on transport must be pursued in order to understand this problem. 


\section{ACKNOWLEDGMENTS}

We gratefully acknowledge the contributions to these studies by all members of the ISX-B Group of the Experimental Confinement Section. Particular thanks are due to M. Murakami, P. W. King, and E. A. Lazarus for Thomson scattering data; to J. B. Wilgen and D. P. Hutchinson for electron concentration data; and to K. H. Burrell for the use of gas injectors provided by the General Atomic Company. W. M. Stacey, Jr., and D. J. Sigmar are credited with motivating the present experiments and their analyses. 
THIS PAGE

WAS INTENTIONALLY

LEFT BLANK 


\section{REFERENCES}

1. W. M. Stacey, Jr., and D. J. Sigmar, Nucl. Fusion 19, 1665 (1979).

2. T. Ohkawa, Impurity Pumping by Beam Injection, GA-A12926, General Atomic Company, San Diego, California (1974).

3. J. B. Wilgen, J. L. Dunlap, D. P. Hutchinson, and D. W. Swain, Bull. Am. Phys. Soc. 24, 1034 (1979).

4. All emission rates are expressed in gigarayleighs $\left(10^{15}\right.$ photons $\left./ \mathrm{cm}^{2}-\mathrm{s}\right)$.

5. R. C. Isler, E. C. Crume, and H. C. Howe, Nucl. Fusion 19, 727 (1979).

6. This behavior is quite the opposite from that observed in ISX-A, where neon introduced as a test gas did not appear to recycle [K. H. Burrell et al., Phys. Rev. Lett. 41, 1382 (1978)]. 


\section{THIS PAGE WAS INTENTIONALLY LEFT BLANK}


ORNL/TM-7472

Dist. Category UC-20 f

INTERNAL DISTRIBUTION

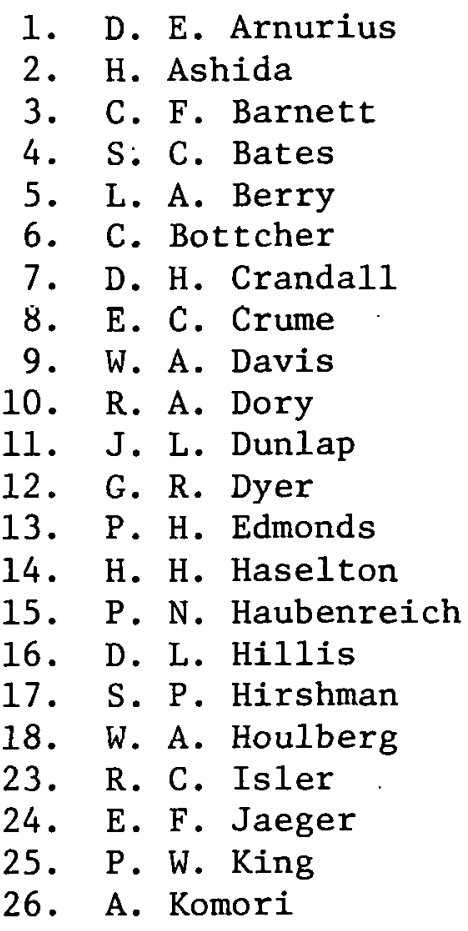
27. R. A. Langley
28. L. L. Lao
29. J. F. Lyon
30. M. Murakami
31. L. E. Murray
32. G. H. Neilson
33. J. A. Rome
34. S. D. Scott
35. J. Sheffield
36. D. J. Sigmar
37. J. E. Simpkins
38. D. W. Swain
39. N. A. Uckan
40-41. Laboratory Records Department
42. Laboratory Records, ORNL-RC
43-44. Central Research Library
45. Fusion Energy Division. Library
46. Fusion Energy Division Reports Office
47. Document Reference Section
48. ORNL Patent Office

\section{EXTERNAL DISTRIBUTION}

49. D. J. Anthony, Energy Systems and Technology Division, Genera1 Electric Company, 1 River Road, Bldg. 23, Room 290, Schenectady, NY 12345

50. R. Bengston, Department of Physics, University of Texas, Austin, TX 78712

51. C. Breton, DPh-PFC/Service du Confinement des Plasmas, Centre d'Etudes Nucleaires, B.P. 6, Fontenay-aux-Roses, France

52. N. Brooks, General Atomic Company, P.0. Box 81608, San Diego, CA 92138

53. J. D. Callen, Nuclear Engineering Department, University of Wisconsin, Engineering Research Building, 1500 Johnson Drive, Madison, WI 53706

54. R. W. Conn, Department of Chemical, Nuclear, and Thermal Engineering, University of California, Los Angeles, CA 90024

55. Czechoslovak Academy of Sciences Institute of Plasma Physics, Pod Vodarenskou Vezi 418069 Prague 8, Czechoslovakia

56. J. N. Davidson, School of Nuclear Engineering, Georgia Institute of Technology, Atlanta, GA 30332

57. N. A. Davies, Tokamak Branch, Office of Fusion Energy, G-234, Department of Energy, Washington, DC 20545

58. S, 0. Dean, Fusion Energy Development, Science Applications, Inc., Suite 249, 2 Professional Drive, Gaithersburg, MD 20760 
59. G. A. Emmert, Nuclear Engineering Department, University of Wisconsin, Engineering Research Building, 1500 Johnson Drive, Madison, WI 53706

60. W. Engelhardt, Max-Planck-Institut für Plasmaphysik, 8046 Garching bei München, Federal Republic of Germany

61. H. K. Forsen, Exxon Nuclear Company, Inc., 777 106th Avenue, NE, Bellevue, WA 98007

62. H. P. Furth, Princeton Plasma Physics Laboratory, P.0. Box 451, Princeton, NJ 08540

63. T. A. Green, Organization 4211, Sandia Laboratories, Albuquerque, NM 87185

64. E. Hinnov, Princeton Plasma Physics Laboratory, P.0. Box 451, Princeton, N.T 08540

65. R. L. Hirsch, Exxon Research and Engineering Company, P.O. Box 101, Fiorhall Fark, HJ 07932

66. A. Hsu, Office of Confinement Systems, Office of Fusion Energy, Department of Energy, Washington, DC 20545

67. H. C. S. Hsuan, Princeton Plas̄ma Physics Laburatory, Princeton University, P.0. Box 451, Princeton, NJ 08540

68. R. Hulse, Princeton Plasma Physics Laboratory, P.0. Box 451, Princeton, NJ 08540

69. R. Huse, Public Service Electric and Gas Company, 80 Park Place, Newark, NJ 07101

70. A. G. Kulchar, University of Tennessee, Knoxville, TN 37916

71. Library, Culham Laboratory, Abingdon, Oxon OX14 3DB, England

72. G. L. Kulcinski, Nuclear Engineering Department, 1500 Johnson Drive, University of Wisconsin, Madison, WI 53706

73. A. L. Merts, T-4, Mail Stop 212, Los Alamos Scientific Laboratory, Los Alamos, NM 87544

74. A. P. Navarro, Division of Fusion, Junta de Energia Nuclear, Madrid 3, Spain

75. E. Oktay, off1ce of Fusion Energy, G-234, Department of Energy, Washington, DC 20545

76. D. Post, Princeton Plasma Physics Laboratory, P.0. Box 451, Princeton, NJ 08540

77. H. Ringler, Max-Planck-Institut für Plasmaphysik, 8046 Garching bei München, Federal Republic of Germany

78. W. Sadowski, Office of Fusion Energy, G-234, Department of Energy, Washington, DC 20545

79. W. M. Stacey, School of Nuclear Engineering, Georgia Institute of T'echnology, Atlanta, GA 30332

80. S. Suckewer, Princeton Plasma Physics Laboracory, P.0. Bux 451, Princetoil, NJ UU540

81. R. J. Taylor, Center for Plasma Physics and Fusion Engineering, University of California, Los Angeles, CA 90024

82. D. P. Tewari, Department of Physics, Ind1an Institute of Technology, New Delhi 110016, India

83. Office of Assistant Manager for Energy Restalcli and Development, Department of Energy, Oak Ridge Operations Office, Oak Ridge, TN 37830

84-275. Given distribution as shown in TID-4500, Magnetic Fusion Energy (Distribution category UC-20 f, Experimental Plasma Physics) 